\title{
Detection of Edible Bird's Nest Using Fourier Transform Infrared Spectroscopy (FTIR) Combined with Principle Component Analysis (PCA)
}

\author{
Noor Atikah S. ${ }^{1}$, Nur Azira T. ${ }^{2 *}$, Nurul Azarima M. A. ${ }^{3}$, Haizatul Hadirah G. ${ }^{4}$, Siti Nur Syahirah Z. ${ }^{5}$ \\ ${ }^{1}$ Department of Biotechnology, Kulliyyah of Science, International Islamic University Malaysia, Bandar Indera \\ Mahkota Campus, Jalan Sultan Ahmad Shah, 25200 Kuantan, Pahang, Malaysia. \\ ${ }^{2}$ International Institute for Halal Research and Training (INHART), Level 3, KICT Building, International \\ University Islamic Malaysia (IIUM), 53100 Jalan Gombak, Selangor, Malaysia \\ ${ }^{5}$ Department of Biomedical Sciences, Kulliyyah of Allied Health Science, International Islamic University \\ Malaysia, Bandar Indera Mahkota Campus, Jalan Sultan Ahmad Shah, 25200 Kuantan, Pahang, Malaysia \\ *Corresponding author: Nur Azira Tukiran, International Institute for Halal Research and Training (INHART), \\ Level 3, KICT Building, International University Islamic Malaysia (IIUM), 53100 Jalan Gombak, Selangor, \\ Malaysia; aziratukiran@iium.edu.my.
}

\begin{abstract}
Edible bird's nest (EBN) is rich in nutrients and health benefits; making it one of the Chinese delicacies over the centuries. However, due to the overpriced and limited supply of EBN, it is being adulterated with other cheaper versions. Therefore, the aim of this study is to establish a method of detecting adulterants in EBN using Fourier transform infrared spectroscopy (FTIR) as the spectrum fingerprinting analysis together with principal component analysis (PCA). Spiked samples have been developed for Tremella fungus and porcine gelatine at the concentrations of $1 \%, 5 \%, 10 \%, 20 \%$ and $30 \%(\mathrm{w} / \mathrm{w})$. The FTIR method combined with PCA analysis was able to detect the adulteration of porcine gelatine and Tremella fungus in the sample of adulterated EBNs at low concentration of $1 \%(\mathrm{w} / \mathrm{w})$. The simple approach employing FTIR combined with PCA may provide a useful tool for EBN detection.
\end{abstract}

Keywords: Edible bird's nest (EBN), authentication, adulteration, Fourier transform infrared spectroscopy (FTIR), principal component analysis (PCA)

Received: $28^{\text {th }}$ May 2020

Accepted: $2^{\text {nd }}$ December 2020

Available Online: $28^{\text {th }}$ December 2020

Citation: Noor Atikah S, Nur Azira Tukiran, Nurul Azarima MA, et al. Detection of edible bird's nest using Fourier Transform Infrared Spectroscopy (FTIR) combined with principle component Analysis (PCA). J Halal Ind Serv 2020; 3(1): a0000168. https://doi.org/10.36877/jhis.a0000168

\section{Introduction}

Edible bird's nest (EBN) is a delicacy and known to provide essential health benefits including enhancing beauty of a person. It has been used as a traditional medicine for the past centuries. EBN are mainly from the species of Collocalia and Aerodramus which can be found in South East Asian countries such as Indonesia, Malaysia, Philippines, Thailand, Vietnam and small part of southern China (Marcone, 2005). The three most common cave nests are A. fuciphagus, A. maximus and C. esculent (Looi \& Omar, 2016). The swiftlet birds 
specifically the male partners produce saliva to build the nest during the breeding season. The feather (also seaweed and mosses) and vegetation were bonded together and cemented using their saliva secreted from their salivary gland. When exposed to air, the sticky secretion hardens forming the bird's nest (Kang et al., 1991). The nest is built in a half-bowl shape from the strands of the solidified saliva thus, enhancing the capabilities of withstanding the bird's eggs and hatchlings (Sidq Ramji et al., 2013).

Known as one of the health-promoting foods in China, which contributes to delicious and scrumptious taste, the composition of EBN has been studied making it among the world's expensive foods. Norhayati et al. (2010), stated that the main nutrients in EBN by $A$. fuciphagus including crude protein, sialic acid and high level of minerals such as calcium, sodium, magnesium, potassium phosphorus, iron, zinc and copper. The potential health effects of EBN have been studied over the years to have biological effects other than antiageing properties. One of the earliest discoveries is an epidermal growth factor (EGF)-like activity, which helps in proliferation, differentiation and target cell's survival (Herbst, 2004; Kong et al., 1987).

The price of the EBN skyrocketed because of the high demand especially from China. According to The Star newspaper in 2017, the processed EBN has soared until RM 10,000/kg from RM 7,000/kg depending on the grade, type and origin. As for the unprocessed bird's nest, the price has increased from RM 1,300/kg to RM 2,700/kg (Wong, 2017). This explained the authentication issues that stirred up among the consumers. In an article by Wong (2013), the authentication of EBN can be of the fake ones, with adulterants and contaminated with bird droppings or any harmful materials to consumers. The common adulterants in EBN can be classified into Type-I and Type-II. Type-I are solid polysaccharides and polypeptides, whereas Type-II are water-soluble saccharides, polypeptides and salts (Shim et al., 2016).

Various studies have been conducted in detecting adulterants in EBN using different methods with different percentage limit detections. These include polymerase chain reaction (PCR) (Guo et al., 2014; Quek et al., 2018), enzyme-linked immunosorbent assays (ELISAs) (Nur Azira et al., 2016), infrared (IR) spectroscopy (Guo et al., 2014; Shi et al., 2017) and gas chromatography/liquid chromatography-mass spectrometry (GC/LC-MS) (Yang et al., 2014). Fourier transform infrared spectroscopy (FTIR) is one of the applications of mid-IR spectroscopy, which can obtain spectra from solid, liquid or gas samples (Paul \& Genesca, 2013). The IR beam was directed onto an optically dense crystal with high refractive index at certain angle. With minimum sample preparations needed, it is known as one of the fastest sampling, higher reproducibility and can minimize user to user spectral variations (Sousa $e t$ al., 2018). However, FTIR produces a complex spectrum, which contains various variables. Therefore, a chemometric methods of principle component analysis (PCA) could allow the characteristics of the sample relationships and classified as a group of same characteristics (Granato et al., 2018). Many studies done have reported the excellent combination of FTIR 
and PCA in food analysis due to feasibility of the results. For instance, detection of lard in "rambak" crackers and determination of thermal effect on oxidation of extra virgin olive oil was successfully determined by PCA (Erwanto et al., 2016; Selaimia et al., 2017). Thus, the integration approach has become a powerful tool and reliable for the meaningful results. This study aims to use FTIR combined with PCA in the detection of adulteration in EBN.

\section{Materials and Methods}

\section{Materials}

Two types of EBN house nest (Collocalia sp.) and cave nest (Aerodramus sp.) were purchased from Malaysia and Indonesia respectively. Tremella fungus (TRE) (dried) was purchased from the local supermarket in Genting Highlands, Pahang, Malaysia. Porcine skin gelatine (P) (G2500-100G, \#058K0109) and bovine skin gelatine (B) (G9391-100G, \#126K0051) were purchased from Sigma-Aldrich (St. Louis, USA). Monosodium glutamate (MSG) powder was purchased from the local supermarket in Selangor, Malaysia. Five different EBN samples are tabulated in Table 1.

Table 1. Samples of EBN

\begin{tabular}{|c|c|c|c|c|c|}
\hline No. & Sample name & Origin & Species & Type & Abbreviation \\
\hline 1 & Cave nest & Indonesia & Aerodramus sp. & Cave nest & $\mathrm{CN}$ \\
\hline 2 & Blood cave nest & Indonesia & Aerodramus sp. & Cave nest & $\mathrm{BC}$ \\
\hline 3 & Orange nest & Malaysia & Collocalia sp. & House nest & ON \\
\hline 4 & White nest 1 & Malaysia & Collocalia sp. & House nest & HOUSE \\
\hline 5 & White nest 2 & Malaysia & Collocalia sp. & House nest & WW \\
\hline
\end{tabular}

\section{Spiked Sample Preparation}

The spiked samples were prepared following the procedure described by Jamalludin and Tukiran (2018), with a slight modification. The EBN samples were grinded using pestle and mortar. TRE was blended using Panasonic MX-SM1031 (240V 50Hz) until it turned into fine powders, while the $\mathrm{P}$ powder was directly taken from the bottle. The spiked samples of TRE and $\mathrm{P}$ were prepared in five concentrations which were 1\%, 5\%, 10\%, $20 \%$ and 30\% (w/w). After that, ON, BC, TRE and P were sieved into finer powders using a $1 \mathrm{~mm}$ sieve to make a constant particle size. The ON powders were weighed using a precision analytical balance. The ON samples were transferred into Eppendorf tube and were mixed using Advanced IR Vortex Mixer (Velp Scientifica, Italy) with the speed of 20x100 rpm for 1 minute. The $\mathrm{ON}$ samples were kept in an airtight bag for further analysis. These steps were also applied for BC, TRE and P.

\section{FTIR}

The FTIR was performed according to Jamalludin and Tukiran (2018). The infrared spectra were analysed in the range between $4000-650 \mathrm{~cm}^{-1}$ with Thermo Scientific Nicolet iS50 FT-IR (ThermoFisher Scientific, Waltham, USA). The OMNIC TM Specta Software (Version 9.2.106) was used to perform FTIR analysis, which gives clear visual data including spectral identification tools, interpretation algorithms and scientific documentation. The 
sample background was run before placing samples into the crystals. Accurately weighed amounts of sample powder were placed on the crystal diamond and making sure the crystal was all covered. All spectra were recorded in absorbance with the resolution of $4 \mathrm{~cm}-1$ at an average of 32 scans. Each sample was analyzed individually in duplicate. The sample was removed using a dry tissue and the surface of FTIR spectrometer was cleaned with methanol before running the sample background.

\section{Statistical Analysis}

The quantitative data were analyzed using Unscrambler ${ }^{\circledR}$ v9.7 CAMO Software AS and the classification of data were performed using PCA. Score plot and loading plot were the outcomes produce by PCA that shows the variability of FTIR data. Fifteen sample variables of wavenumber $\left(\mathrm{cm}^{-1}\right)$ of $1633 \mathrm{~cm}^{-1}, 1602 \mathrm{~cm}^{-1}, 1518 \mathrm{~cm}^{-1}, 1516 \mathrm{~cm}^{-1}, 1444 \mathrm{~cm}^{-1}$, $1442 \mathrm{~cm}^{-1}, 1434 \mathrm{~cm}^{-1}, 1415 \mathrm{~cm}^{-1}, 1336 \mathrm{~cm}^{-1}, 1247 \mathrm{~cm}^{-1}, 1248 \mathrm{~cm}^{-1}, 1241 \mathrm{~cm}^{-1}, 1029 \mathrm{~cm}^{-1}$, $875 \mathrm{~cm}^{-1}$, and $704 \mathrm{~cm}^{-1}$ were chosen for the PCA, since these wavenumbers $\left(\mathrm{cm}^{-1}\right)$ have either similarities or differences in spectrum between each sample.

\section{Results}

\section{FTIR Spectra}

Pure EBN

Five types of EBN spectral were compared as shown in Figure 1. The region between $3600-3100 \mathrm{~cm}^{-1}$ can be compensated for the water (O-H stretching) like those reported by Hamzah et al. (2013). This indicated that water molecules were present in EBN although the samples were in powdered form. Between the region of 2100 and $2160 \mathrm{~cm}^{-1}$, only ON and HOUSE samples produced a significant peak at that region. Region $876-875 \mathrm{~cm}^{-1}$ was significant for all CN and almost disappeared in HOUSE (Guo et al., 2017). Different wavenumber produced from the absorbance peaks might be contributed from asymmetric stretching vibrations of $\mathrm{CH} 2\left(2934 \mathrm{~cm}^{-1}\right), \mathrm{CH}_{2}$ stretching lipids $\left(2855 \mathrm{~cm}^{-1}\right), \mathrm{C}=\mathrm{O}$ triglycerides $\left(1745 \mathrm{~cm}^{-1}\right)$, stretching vibration of $\mathrm{C}=\mathrm{O}$ bond of amide $\mathrm{I}\left(1654 \mathrm{~cm}^{-1}\right)$ and $\mathrm{N}-\mathrm{H}$ bending vibration for amide II band $\left(1545 \mathrm{~cm}^{-1}\right)$, bending vibration $\mathrm{CH}_{2}$ in polysaccharides $\left(1430 \mathrm{~cm}^{-1}\right)$, symmetric stretching vibration of COO- groups of fatty acids and amino acids $\left(1400-1300 \mathrm{~cm}^{-1}\right)$, phosphate vibration of nucleic acids $\left(1235 \mathrm{~cm}^{-1}\right), \mathrm{C}-\mathrm{O}$ stretching vibration coupled with $\mathrm{C}-\mathrm{O}$ bending of the $\mathrm{C}-\mathrm{OH}$ groups of carbohydrates $\left(1045 \mathrm{~cm}^{-1}\right), \mathrm{CH}$ out-ofplane bending vibrations (1000-700 $\left.\mathrm{cm}^{-1}\right)$ (Guo et al., 2017; Hamzah et al., 2013; Movasaghi et al., 2008). All samples exhibit almost similar spectrum in the fingerprint region $>1500$ $\mathrm{cm}^{-1}$ thus showed the presence of similar compounds. 


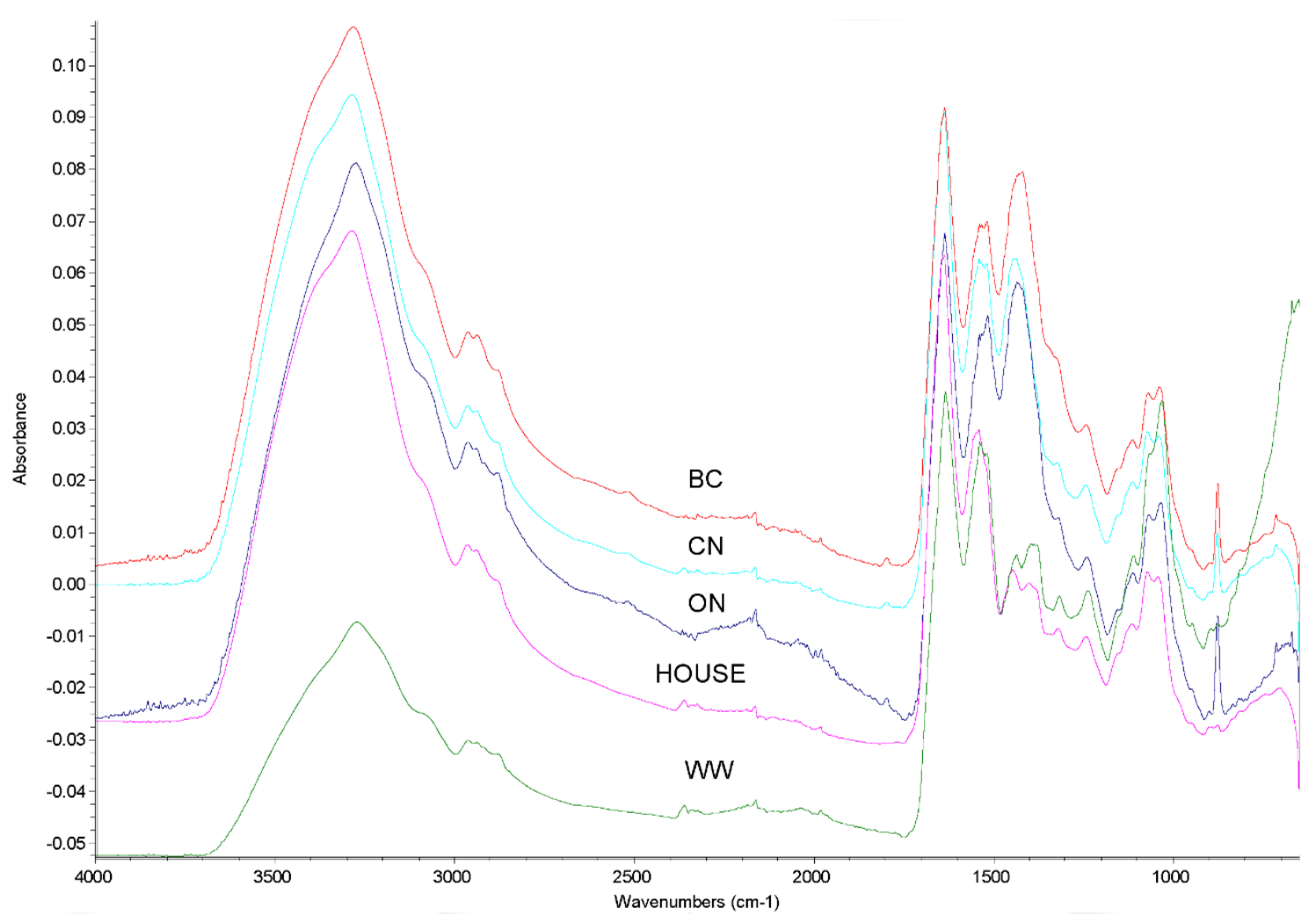

Figure 1. Overlapped spectrum of cave nest (Aerodramus sp.) and house nest (Collocalia sp.). BC: blood cave nest, CN: cave nest; ON: orange nest; HOUSE: white nest 1; and WW: white nest 2

Based on Figure 1, the peaks between $1635-1634 \mathrm{~cm}^{-1}$ were accounted for amide I and $1539-1515 \mathrm{~cm}^{-1}$ were accounted for amide II. The peaks $1445-1434 \mathrm{~cm}^{-1}$ and $1417-1393$ $\mathrm{cm}^{-1}$ might indicate the presence of carboxylic $(\mathrm{COOH})$ and aldehydes $(\mathrm{CH}=\mathrm{O})$, respectively. The peak at 1070-1030 $\mathrm{cm}^{-1}$ were the resulting vibrations of polysaccharides (C-O bonds), which has proven the presence of carbohydrates in EBN as reported by Hamzah et al. (2013) and Set (2012). As shown, there were no obvious spectral features that can be recorded, except for the varieties of different spectrum in the region between $1800-700 \mathrm{~cm}^{-1}$. The results for amide I and amide II were similar from the reported value $1600-1700 \mathrm{~cm}^{-1}$ and 1560-1335 cm-1 (Hamzah et al., 2013; Shi et al., 2017).

\section{Adulterants}

Four adulterants namely, TRE, MSG, P and B were compared. Figure 2 exhibits that TRE was significant at $1415 \mathrm{~cm}^{-1}$ (COOH bend or stretch), while MSG produced the highest number of spectra, which was easily being distinguished at $2050 \mathrm{~cm}^{-1}(\mathrm{C}=\mathrm{C}$ stretch $), 857 \mathrm{~cm}^{-}$ ${ }^{1}$ and $655 \mathrm{~cm}^{-1}$ among other adulterants. The exhibited spectrum was similar with the reported spectrum in National Institute of Standards and Technology (NIST) Chemistry WebBook (2018). $\mathrm{P}$ and $\mathrm{B}$ can be distinguished at $1634-1633 \mathrm{~cm}^{-1}$ (C=O stretch), $1337-1336 \mathrm{~cm}^{-1}$ (C$\mathrm{N}$ bond) and $1081 \mathrm{~cm}^{-1}$ (C-O bond), which were not shown in other adulterants. Hence, it can be concluded that, $\mathrm{P}$ and $\mathrm{B}$ showed similar spectrum with different absorbance values. Hashim et al. (2010) and Eryilmaz et al. (2017) also mentioned that P and B can be found 
similar in region $1656-1644 \mathrm{~cm}^{-1}$ (amide I), $1560-1335 \mathrm{~cm}^{-1}$ (amide II) and 1240-670 $\mathrm{cm}^{-1}$ (amide III).

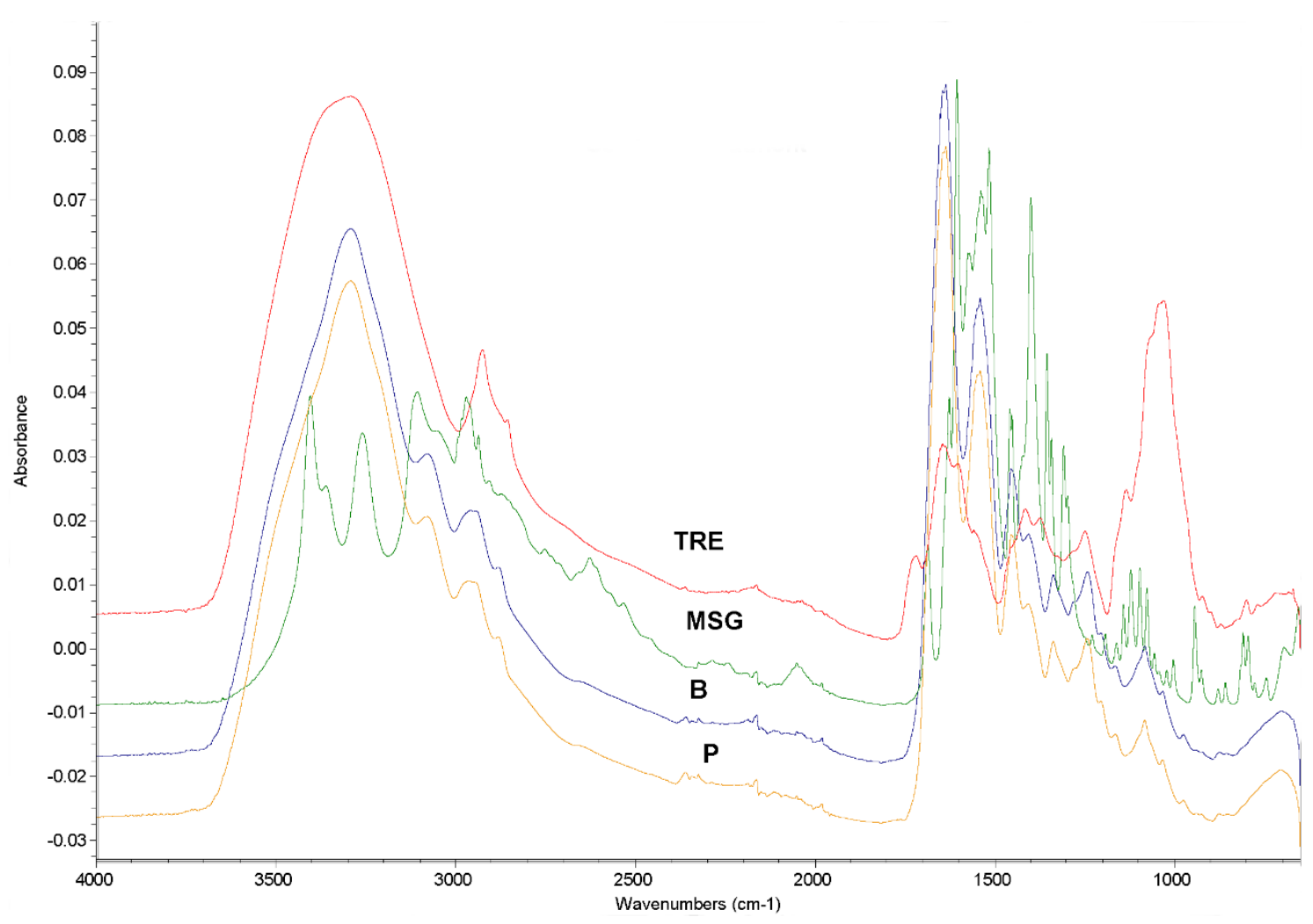

Figure 2. The overlapped spectrum of different types of adulterants. TRE: Tremella fungus; MSG: monosodium glutamate; B: bovine gelatine; and P: porcine gelatine.

\section{Adulterated spiked samples}

Figure 3 (a) and (b) represent the $\mathrm{P}$ adulterant that can be denoted at $1539 \mathrm{~cm}^{-1}, 1453-$ $1444 \mathrm{~cm}^{-1}$ and $1081-1070 \mathrm{~cm}^{-1}$ for all $\mathrm{P}$ percentages in $\mathrm{ON}$ and $\mathrm{BC}$. Meanwhile, the adulteration of TRE in $\mathrm{ON}$ and $\mathrm{BC}$ exhibited similar spectrum with the samples of the pure BC and ON illustrated by Figure 4 (a) and (b). Thus, further analysis using PCA is required to identify the adulteration of $\mathrm{P}$ and TRE in $\mathrm{ON}$ and $\mathrm{BC}$. 


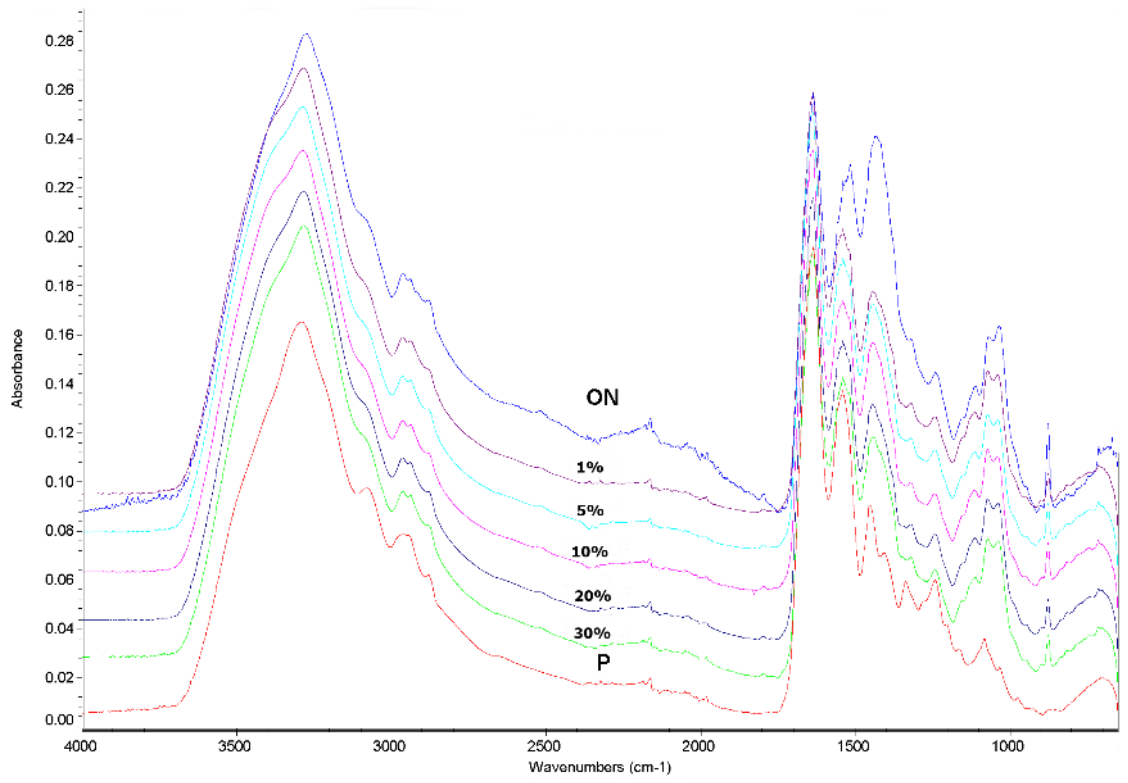

(a)

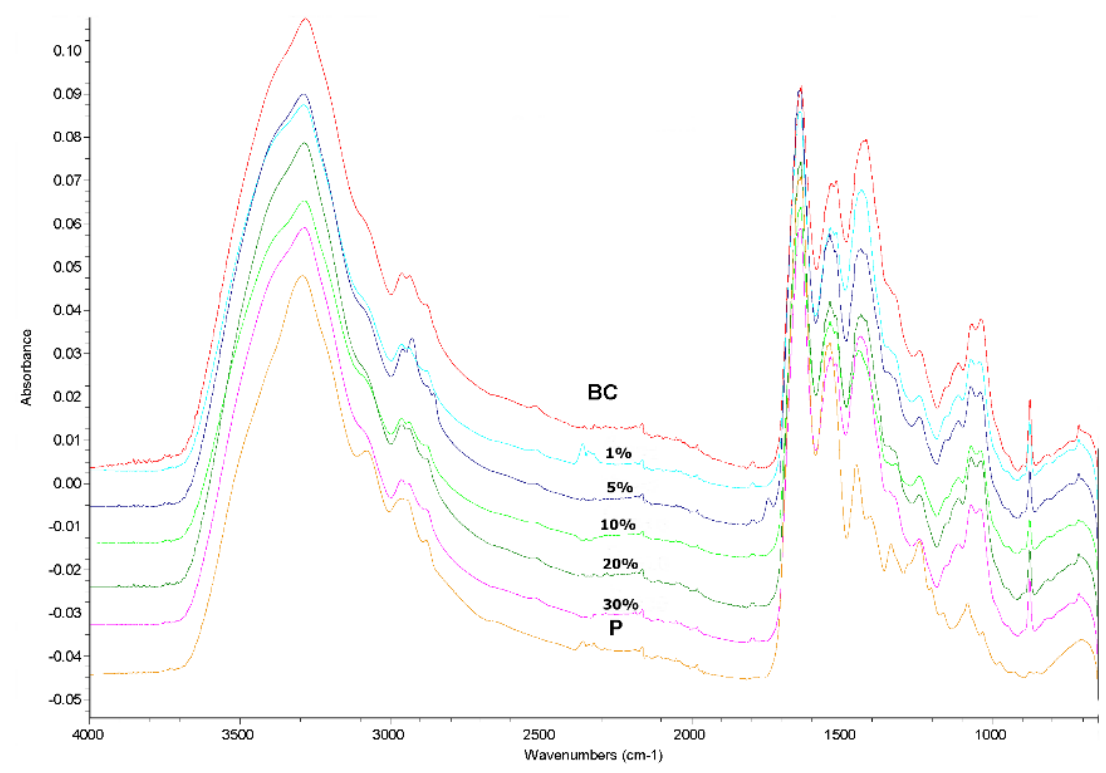

(b)

Figure 3. The overlapped spectrums of edible bird's nest (EBN) adulterated with different percentage of porcine gelatine (P). (a) Orange nest (ON); and (b) blood cave nest (BC). 


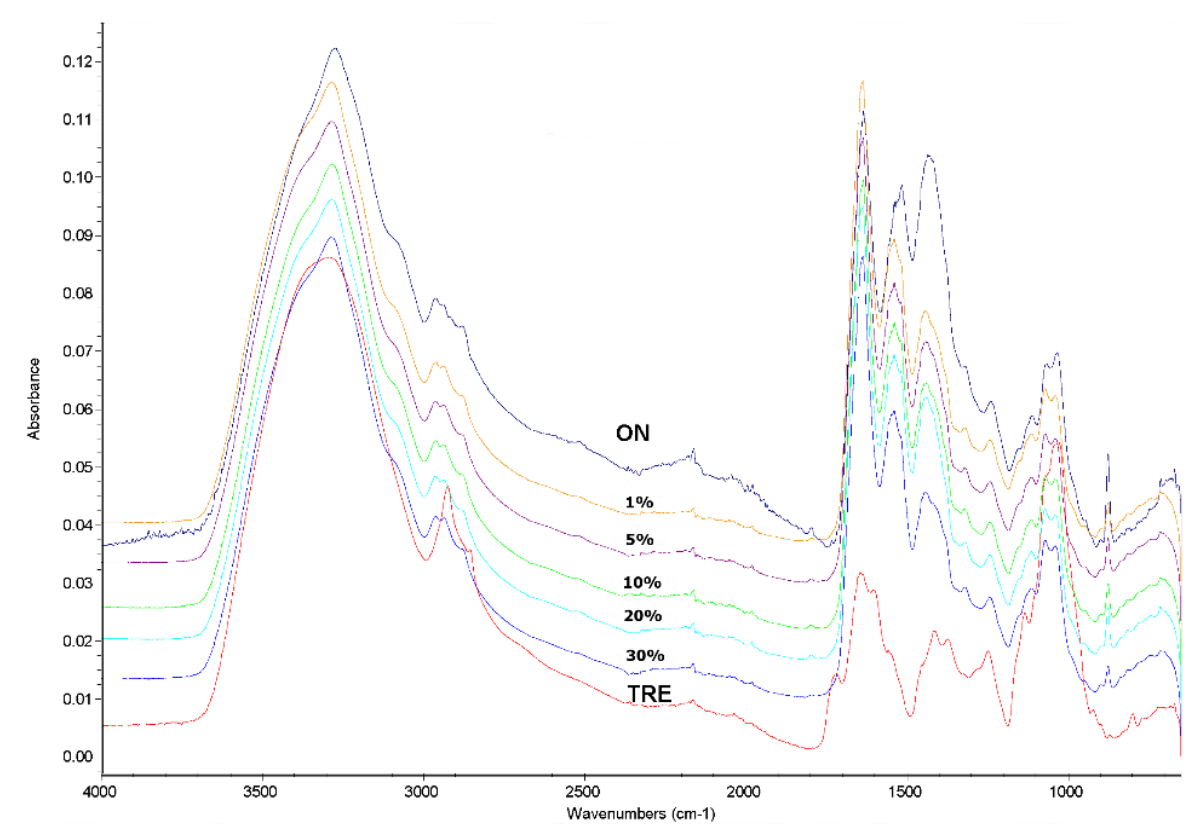

(a)

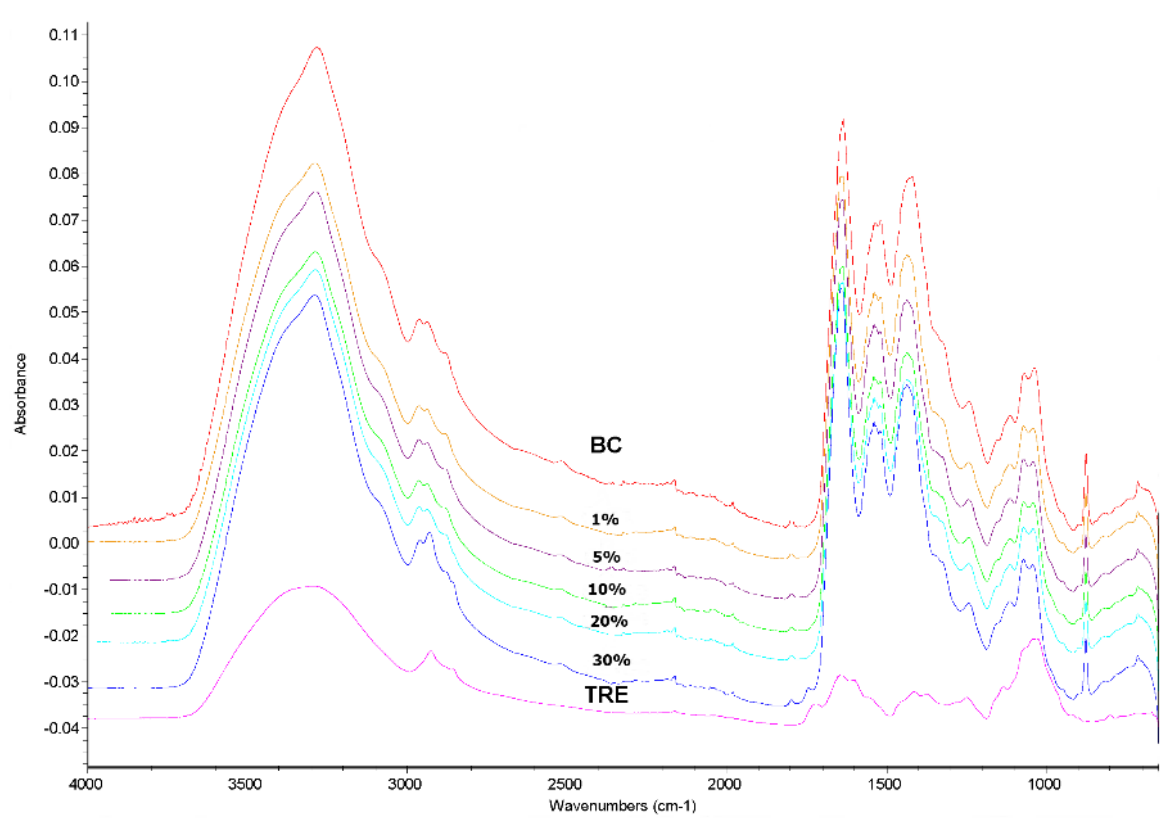

(b)

Figure 4. The overlapped spectrums of edible bird's nest (EBN) adulterated with different percentage of Tremella fungus (TRE). (a) Orange nest (ON); and (b) blood cave nest (BC).

\section{Principle Component Analysis (PCA)}

The PCA is one of the chemometric analysis, which utilizes low dimensional space (principle components) of the new latent variables from a larger dimensional data. The first 
principle components (PC1) represented the highest variance in a data set and the second highest data set was grouped in the second principle components (PC2). The number of variables can be reduced by this method, which gives the graphical representation of the data. The results were presented in terms of loading plots, which showed the contribution of the variables to a given PC and the score plots, which showed the projections of the objects and the similarities can be measured among them (Massart et al., 1997; Norhayati et al., 2010). Fifteen variables were chosen to represent significance for each sample. Those wavenumber variables of $1633 \mathrm{~cm}^{-1}, 1602 \mathrm{~cm}^{-1}, 1518 \mathrm{~cm}^{-1}, 1516 \mathrm{~cm}^{-1}, 1444 \mathrm{~cm}^{-1}, 1442 \mathrm{~cm}^{-1}, 1434 \mathrm{~cm}^{-1}$, $1415 \mathrm{~cm}^{-1}, 1336 \mathrm{~cm}^{-1}, 1247 \mathrm{~cm}^{-1}, 1248 \mathrm{~cm}^{-1}, 1241 \mathrm{~cm}^{-1}, 1029 \mathrm{~cm}^{-1}, 875 \mathrm{~cm}^{-1}$, and $704 \mathrm{~cm}^{-1}$ had shown either significant similarities or differences between each sample.

In Figure 5 and Figure 6, the PCA could differentiate between the samples when ON and $\mathrm{BC}$ adulterated with $\mathrm{P}$ and TRE. The samples were classified into three groups in the PCA, where the group I represents the pure samples of ON or BC, group II represents either $\mathrm{P}$ or TRE and group III represents the adulterated samples with 1\%, 5\%, 10\%, $20 \%$ and 30\% of P or TRE. Figure 5 (a) and (c) of ON samples adulterated with P and TRE show that 97\% and $99 \%$ of the variation were accounted for $\mathrm{PC} 1$ and $3 \%$ and $1 \%$ of the variation were accounted for PC2, respectively. Meanwhile, based on the Figure 6 (a) and (c), the results of BC samples adulterated with P and TRE show that PC1 accounted for about $95 \%$ and $100 \%$ of the variation and PC2 accounted for about $3 \%$ and $0 \%$ of the variation, respectively. Both score plots of $\mathrm{P}$ and TRE samples were located at the positive side of $X$-axis, however, $\mathrm{P}$ was located below $X$-axis, while TRE was located above $X$-axis. Hence, the PCA in both ON and $\mathrm{BC}$ samples was able to detect the grouping, similarities and differences of the input data even at low adulterants concentration at $1 \%$.

In addition, the variables that were located farther from the origin of PCA loading plots have strong contributions for the PCA model (Marina et al., 2010). Figure 5 (b), 6 (b) and 8 (d) showed that the wavenumbers of $1602 \mathrm{~cm}^{-1}$ and $1633 \mathrm{~cm}^{-1}$ have high contributions, indicating the separation of the samples between the adulterants and EBN samples. However, the loading plot of ON adulterated with TRE in Figure 5 (d) showed that $1633 \mathrm{~cm}^{-1}$ weakly contributed to the model, however, $1602 \mathrm{~cm}^{-1}$ contributes a strong influence on the variation of the samples. This might suggest that both adulteration in $\mathrm{ON}$ and $\mathrm{BC}$ with $\mathrm{P}$ and TRE can be differentiated through the variables that have strong contribution for the PCA model. 

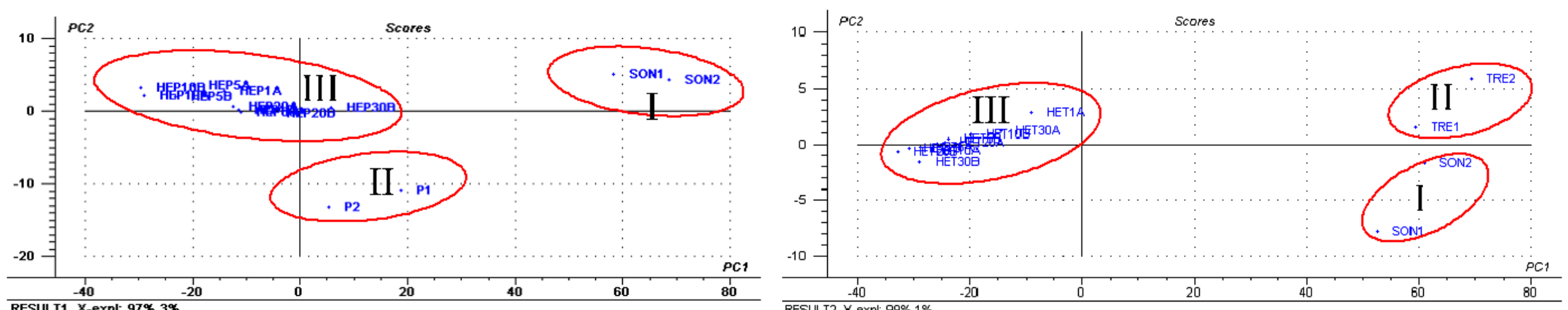

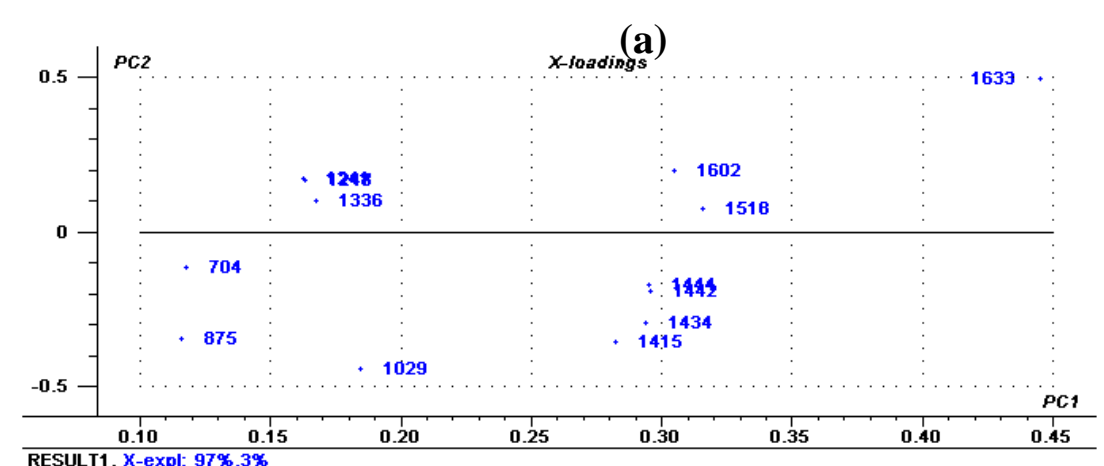

(b)

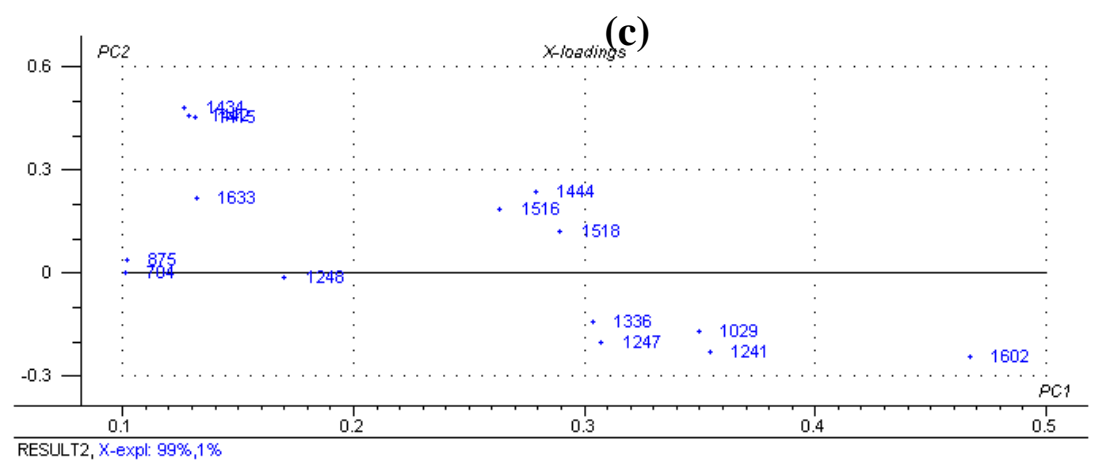

(d)

Figure 5. PCA grouping of orange nest $(\mathrm{ON})$ adulterated with porcine gelatine (P) and Tremella fungus (TRE). (a and b) Score plots and loading plots for PCA grouping of orange nest $(\mathrm{ON})$ adulterated with porcine gelatine $(\mathrm{P})$ (c and d) Score plots and loading plots for PCA grouping of orange nest (ON) adulterated with Tremella fungus (TRE). Group I: orange nest; group II: porcine gelatine or Tremella fungus; group III: adulterated orange nest with porcine gelatine or Tremella fungus percentage. 


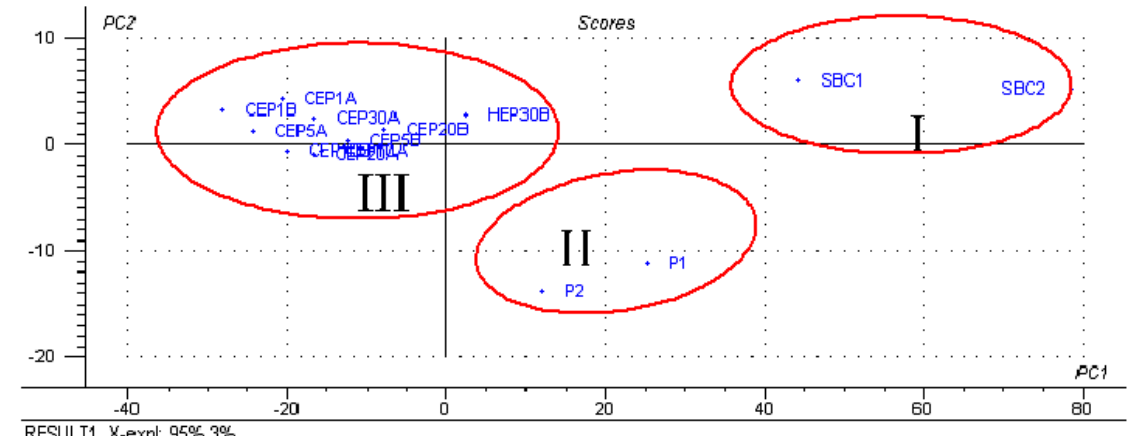

(a)

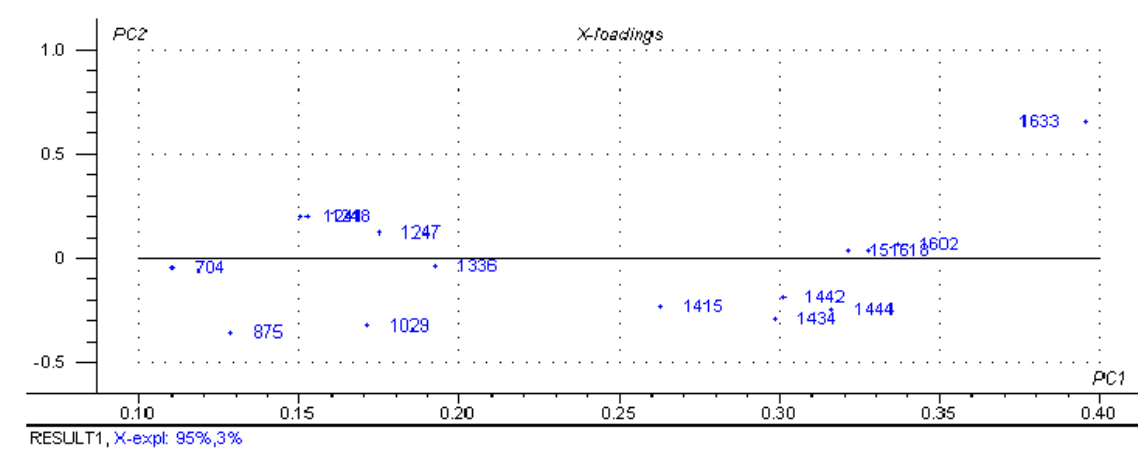

(b)

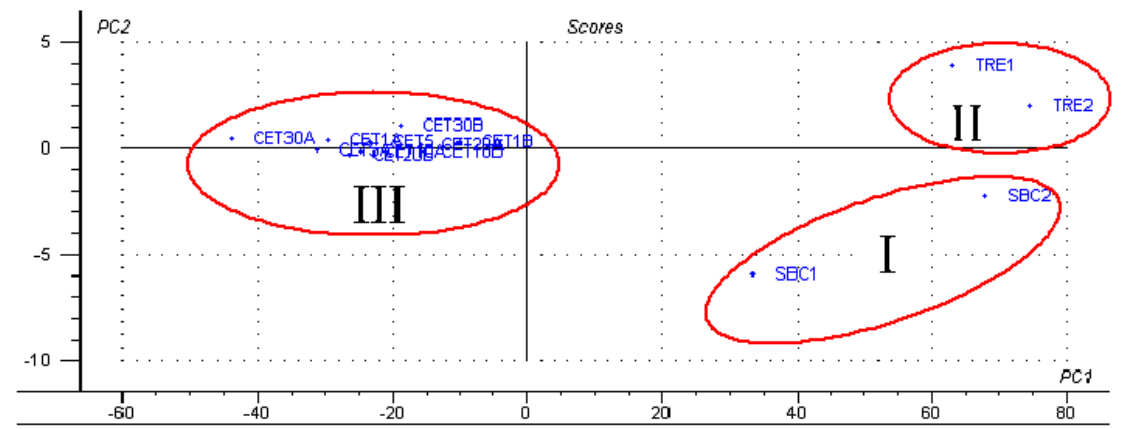

(c)

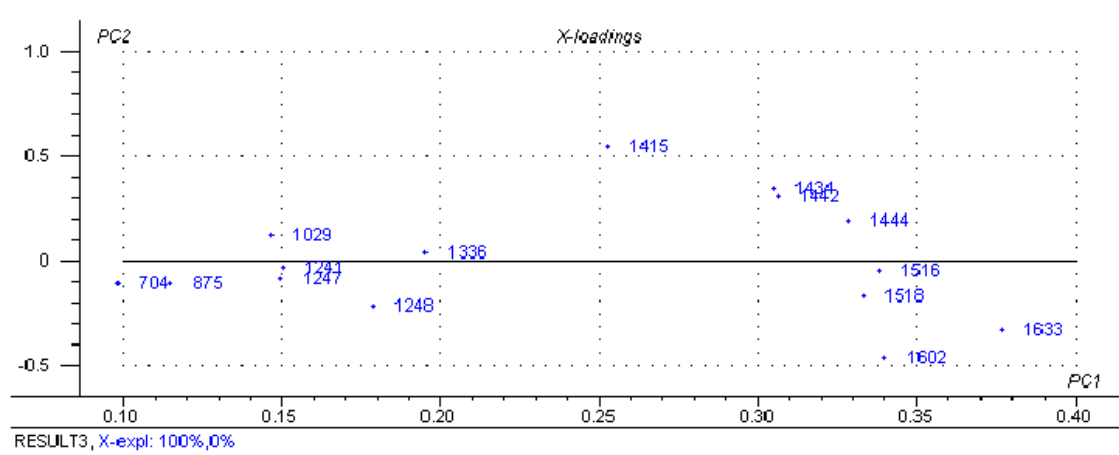

(d)

Figure 6. PCA grouping of blood cave nest (BC) adulterated with porcine gelatine (P) and Tremella fungus (TRE). (a and b) Score plots and loading plots for PCA grouping of blood cave nest (BC) adulterated with porcine gelatine $(\mathrm{P})(\mathrm{c}$ and d) Score plots and loading plots for PCA grouping of blood cave nest (BC) adulterated with Tremella fungus (TRE). Group I: blood cave nest; group II: porcine gelatine or Tremella fungus; group III: adulterated blood cave nest with porcine gelatine or Tremella fungus percentage 


\section{Conclusion}

Fourier transform infrared spectroscopy (FTIR) is a reliable, fast and easy to use fingerprinting technique that can be applied for food authentication. The Principal Component Analysis (PCA) analysis can further concluded and differentiated EBN, adulterants and different concentration of adulterations for porcine $(\mathrm{P})$ and Tremella fungus (TRE) in the edible bird's nest (EBN). This study showed that the presence of $\mathrm{P}$ and TRE adulterants in orange nest $(\mathrm{ON})$ and blood cave nest $(\mathrm{BC})$ can be detected as low as $1 \%(\mathrm{w} / \mathrm{w})$ concentration through the significant distinction of the grouping in the PCA. The wavenumbers of $1602 \mathrm{~cm}^{-1}$ and $1633 \mathrm{~cm}^{-1}$ show high contribution to the separation between the adulterants and EBN samples. To conclude, FTIR with the combination of PCA is a reliable tool in authenticating EBN.

Acknowledgements: This work was supported by the IIUM Research Initiative Grant Scheme [RIGS16-0680232] from the International Islamic University Malaysia (IIUM), Selangor, Malaysia.

Conflicts of Interest: The authors declare no conflict of interest.

\section{References}

Erwanto, Y., Muttaqien, A. T., Sugiyono, et al. (2016). Use of Fourier Transform Infrared (FTIR) Spectroscopy and Chemometrics for Analysis of Lard Adulteration in "Rambak" Crackers. International Journal of Food Properties, 19(12), 2718-2725. Doi: https://doi.org/10.1080/10942912.2016.1143839

Eryılmaz, H. S., Işı1k, B. Ş., Demircan, E., et al. (2017). Origin Determination and Differentiation of Gelatine Species of B, P, and Piscine through Analytical Methods. Turkish Journal of Agriculture-Food Science and Technology, 5(5), 507-517.

Granato, D., Putnik, P., Kovačević, D. B., et al. (2018). Trends in Chemometrics: Food Authentication, Microbiology, and Effects of Processing. Comprehensive Reviews in Food Science and Food Safety, 17(3), 663-677. Doi: https://doi.org/10.1111/1541-4337.12341

Guo L., Wu Y., Liu M., et al. (2017). Rapid Authentication of Edible Bird's Nest by FTIR Combined with Chemometrics. 98(8), 3057-3065. Doi: https://doi.org/10.1002/jsfa.8805

Guo, L., Wu, Y., Liu, M., et al. (2018). Rapid authentication of edible bird's nest by FTIR combined with chemometrics. Journal of the Science of Food and Agriculture, 98(8), 3057-3065. Doi: https://doi.org/10.1002/jsfa.8805

Guo, L., Wu, Y., Liu, M., et al. (2014). Authentication of Edible Bird's nests by TaqMan-based real-time PCR. Food Control, 44, 220-226. Doi: https://doi.org/10.1016/j.foodcont.2014.04.006

Hamzah, Z., Jeyaraman, S., Ibrahim, N. H., et al. (2013). A rapid technique to determine purity of edible bird nest. Advances in Environmental Biology, 7(SPEC. ISSUE 12), 3758-3765.

Hashim, D. M., Che Man, Y. B., Norakasha, R., et al. (2010). Potential use of fourier transform infrared spectroscopy for differentiation of bovine and porcine gelatins. Food Chemistry, 118, 856-860. https://doi.org/10.1016/j.foodchem.2009.05.049 
Herbst, R. S. (2004). Review of epidermal growth factor receptor biology. International Journal of Radiation Oncology Biology Physics, 52(2), S21-S26. Doi: https://doi.org/10.1016/j.ijrobp.2003.11.041

Jamalludin, N. H., \& Tukiran, N. A. (2018). Analysis of gelatin adulteration in edible bird's nest using fourier transform infrared (FTIR) spectroscopy. International Journal on Advance Science Engineering Information Technology, 8(6), 2355-2359.

Kang, N., Hails, C. J., \& Sigurdsson, J. B. (1991). Nest construction and egg-laying in edible-nest swiftlets Aerodramus spp. and the implications for harvesting. Ibis, 133(2), 170-177.

Kong, Y. C., Keung, W. M., Yip, T. T., et al. (1987). Evidence that epidermal growth factor is present in swiftlet's (Collocalia) nest. Comparative Biochemistry and Physiology -- Part B: Comparative and Biochemistry, 87(2), 221-226. Doi: https://doi.org/10.1016/0305-0491(87)90133-7

Looi, Q. H., \& Omar, A. R. (2016) Swiftlets and edible bird's nest industry in Asia. Pertanika Journal of Scholarly Research Reviews, 2(1), 32-48.

Marcone, M. F. (2005). Characterization of the edible bird's nest the "Caviar of the East." Food Research International, 38(10), 1125-1134. Doi: https://doi.org/10.1016/j.foodres.2005.02.008

Marina, A.M., Che Man, Y.B., \& Amin, I. J. (2010). Use of the SAW Sensor Electronic Nose for Detecting the Adulteration of Virgin Coconut Oil with RBD Palm Kernel Olein. Journal of the American Oil Chemists' Society, 87(3), 263-267. Doi: https://doi.org/10.1007/s11746-009-1492-2

Massart, D. L., Vandeginste, B. G., Buydens, L. M. C., et al. (1997). Handbook of Chemometrics and Qualimetrics: Part a. Elsevier Science Inc., New York, NY, USA.

Movasaghi, Z., Rehman, S., \& Rehman, I. ur. (2008). Fourier transform infrared spectroscopy of biological tissues. Applied Spectroscopy Reviews, 43(2), 134-179.

National Institute of Standards and Technology (NIST). (2018). Retrieved on July 23, 2019 from https://webbook.nist.gov/cgi/cbook.cgi?ID=B6004640\&Mask=80\#copyright

Norhayati, M. K. J., Azman, O., \&Wan Nazaimoon, W. (2010). Preliminary Study of the Nutritional Content of Malaysian Edible Bird's Nest. Malaysian Journal of Nutrition, 16(3), 389-396.

Nur Azira, T., Amin, I., Shuhaimi, M., et al. (2016). Determination of porcine gelatine in edible bird's nest by competitive indirect ELISA based on anti-peptide polyclonal antibody. Food Control, 59, 561-566. Doi: https://doi.org/10.1016/j.foodcont.2015.06.039

Paul, R., \& Genescà, E. (2013). The use of enzymatic techniques in the finishing of technical textiles. In: Advances in the Dyeing and Finishing of Technical Textiles. Woodhead Publishing Series in Textiles. pp. 177-198. Doi: https://doi.org/10.1533/9780857097613.2.177

Quek, M. C., Chin, N. L., Tan, S. W., et al. (2018). Molecular identification of species and production origins of edible bird's nest using FINS and SYBR green I based real-time PCR. Food Control, 84, 118-127. Doi: https://doi.org/10.1016/j.foodcont.2017.07.027

Selaimia, R., Oumeddour, \& R., Nigri, S. (2017). The chemometrics approach applied to FTIR spectral data for the oxidation study of Algerian extra virgin olive oil. International Food Research Journal, 24(3), 13011307. 
Set, J. (2012). Fast, Effective Evaluation of Edible Bird's Nest Using the Handheld Agilent 4100 Exoscan FTIR. Agilent Technologies Petaling Jaya, Malaysia.

Shi, J., Zhang, F., Li, Z., et al. (2017). Rapid authentication of Indonesian edible bird's nests by near-infrared spectroscopy and chemometrics. Analytical Methods, 9(8), 1297-1306.

Shim, E. K. S., Chandra, G. F., Pedireddy, S., et al. (2016). Characterization of swiftlet edible bird nest, a mucin glycoprotein, and its adulterants by Raman microspectroscopy. Journal of Food Science and Technology, 53(9), 3602-3608. Doi: https://doi.org/10.1007/s13197-016-2344-3

Sidq Ramji, M.F., Koon, L. C., \& Abdul Rahman, M. (2013). Roosting and nest-building behaviour of the white-nest swiftlet Aerodramus Fuciphagus (Thunberg) (Aves: Apodidae) in farmed colonies. The Raffles Buletin of Zoology, 9, 225-235.

Sousa, N., Moreira, M., Saraiva, C., et al. (2018). Applying fourier transform mid infrared spectroscopy to detect the adulteration of Salmo salar with Oncorhynchus mykiss. Foods, 7(4), 55. Doi: https://doi.org/10.3390/foods7040055

Wong, J. (2017). Bird's Nest Prices Soar After China Lifts Import Ban. The Star Online. Retrieved from https://www.thestar.com.my/business/business-news/2017/12/18/birds-nest-prices-soar-after-chinalifts-import-ban/

Wong, R. S. Y. (2013). Edible bird's nest: Food or medicine? Chinese Journal of Integrative Medicine, 19(9), 643-649. Doi: https://doi.org/10.1007/s11655-013-1563-y

Yang, M., Cheung, S.-H., Li, S. C., et al. (2014). Establishment of a holistic and scientific protocol for the authentication and quality assurance of edible bird's nest. Food Chemistry, 151, 271-278. Doi: https://doi.org/10.1016/j.foodchem.2013.11.007 